\title{
Viabilidade de tubérculos de tiririca (Cyperus rotundus) tratados com sulfentrazone e flazasulfuron
}

\author{
Viability of the tubers of purple nutsedge (Cyperus rotundus L.) treated with \\ sulfentrazone and flazasulfuron
}

\author{
Waldinei Pastre ${ }^{1}$; Robert Deuber ${ }^{2}$; José Carlos Rolim ${ }^{3}$
}

\begin{abstract}
Resumo - A utilização de herbicidas para o controle de plantas infestantes evoluiu muito nos últimos anos, principalmente para aquelas de difícil manejo como a tiririca (Cyperus rotundus L.). O objetivo deste trabalho foi estudar a eficácia de sulfentrazone e flazasulfuron isoladamente e em mistura, na redução da viabilidade de tubérculos de tiririca, após uma aplicação e reaplicação dos tratamentos após um ano. Os produtos foram aplicados em pós-emergência inicial da ciperácea (4 a 5 folhas). Foram avaliados os dados relativos à viabilidade dos tubérculos de $C$. rotundus, coletado na camada arável $(25 \times 25 \times 25 \mathrm{~cm})$, e levados para casa-devegetação, onde foram plantados em badejas de isopor contendo 128 células, avaliando-se o percentual de germinação 20 dias após o plantio dos tubérculos. Os resultados demonstraram que os herbicidas causaram reduções significativas na viabilidade de tubérculos de tiririca. Os melhores resultados foram obtidos pelo herbicida flazasulfuron na dose de $50{\mathrm{~g} . h a^{-1}}^{\mathrm{e}} \mathrm{em}$ aplicações seqüenciais de $50+50 \mathrm{~g}^{\mathrm{h}} \mathrm{ha}^{-1}$.
\end{abstract}

Palavras-chave: Triazolinone, Cyperaceae, sulfoniluréia.

Abstract - The use of herbicides for weed control have improved in the last years, mainly for the control of purple nutsedge (Cyperus rotundus L.) and other perennial weeds. In order to study the control of purple nutsedge, sulfentrazone and flazasulfuron isolated and in mixture, were applied in field conditions with high infestation of this species and repeated on the second year. The variable analysed were viability of the tubers of $C$. rotundus at 90 and 300 DAT in 2004 and at 90 and 270 DAT in 2005 , collected in the arable layer $(25 \times 25 \times 25 \mathrm{~cm})$, and taken to a greenhouse where they were planted. Evaluation of the percentage of germination was done at 20 days after the planting of the tubers of $C$. rotundus. The results showed that the herbicides provided significant reductions of the tubers viability of purple nutsedge. Best control was achieved with flazasulfuron at 50 g.ha ${ }^{-1}$ and flazasulfuron at $50+50$ g.ha $^{-1}$ in sequential applications.

Key-words: triazolinone, cyperaceae, sulfonylurea.

\footnotetext{
${ }^{1}$ Eng. Agr., MSc pela Pós-Graduação do Instituto Agronômico (IAC) Campinas-SP; e-mail: wpastre@ yahoo.com.br

${ }^{2}$ Pesquisador Científico, IAC - Centro de Ecofisiologia e Biofísica (IAC), Campinas-SP; e-mail: rdeuber@iac.sp.gov.br

${ }^{3}$ Professor do Centro de Ciências Agrárias da Universidade Federal de São Carlos, Campus de Araras-SP; e-mail: jcrolim@vivax.com.br
} 


\section{Introdução}

Para o controle de plantas infestantes em áreas cultivadas, as aplicações em préemergência ou em pós-emergência inicial são as mais indicadas para a diminuição da população das infestantes, especialmente em gramíneas. A população de plantas infestantes, bem como a intensidade de ocorrência, são fatores importantes para a definição dos produtos a serem utilizados para seu manejo.

A tiririca (Cyperus rotundus L.) é considerada por Holms et al. (1977) como uma das principais daninhas em diversas culturas no mundo devido a sua ampla distribuição, capacidade de competição, longevidade de seus tubérculos (Baruian et al., 1999), agressividade, assim como pela dificuldade em ser controlada ou erradicada (Bendixen \& Nandihalli, 1987; Stoller \& Sweet, 1987; Kissmann, 1997; Lorenzi, 2000).

Muitas culturas de importância econômica são afetadas pela presença da tiririca entre elas a cana-de-açúcar. Cerca de um milhão de hectares de cana-de-açúcar apresentam infestação por tiririca no Brasil (Durigan et al., 2006). Segundo Arevalo (1996) em $40 \%$ da área canavieira a infestação é baixa (menos de 100 plantas por $\mathrm{m}^{2}$ ), $31 \%$ apresentam média infestação (100 - 500 plantas $\mathrm{m}^{2}$ ) e $29 \%$ com alta infestação (mais de 500 plantas por $\mathrm{m}^{2}$ ). Embora o prejuízo que a tiririca causa no desenvolvimento da cultura e, por conseqüência, na produção seja decorrente da competição exercida durante todo o ciclo, ela é mais prejudicial na fase inicial do desenvolvimento das culturas (Kissmann, 1997). Além de competir com a cultura, apresenta exsudação de substâncias químicas no solo com efeito alelopático, inibindo a brotação de gemas e reduzindo o desenvolvimento dos perfilhos da cana-deaçúcar, o que resulta em estandes com menor número de indivíduos nas áreas infestadas
(Dario et al., 1995; Catunda et al., 2000; Silva et al.,2000).

C. rotundus é uma planta perene que produz numerosas sementes mas estas raramente são viáveis (Wills, 1975) devido principalmente à falta de vigor de suas plântulas, (Stoller \& Wax, 1973). Em áreas de cultura de cana-de-açúcar tem sido observado multiplicação de tiririca por sementes em sulcos onde foi aplicado torta de filtro de usinas de açúcar, ou seja, em áreas com elevado teor de matéria orgânica e de umidade adequada. Entretanto, sua reprodução ocorre, principalmente, por rizomas e tubérculos (Kissmann,1997; Deuber, 2003).

Segundo Machado et al. (2006), o preparo do solo no sistema de plantio convencional favorece a propagação e o estabelecimento da tiririca devido à fragmentação dos tubérculos e distribuição pelos implementos e quebra de dormência, através da eliminação da dominância apical. Em experimentos realizados em caixa de cimento amianto por Rolim et al. (2002), foi verificado incremento de até $300 \%$ na massa verde dos tubérculos da tiririca após 75 dias do plantio desta espécie. A adição de palha de cana-de-açúcar no solo ocasionou redução no número de rizomas e de tubérculos + bulbos basais sendo observado que os menores valores foram obtidos com a quantidade de palha equivalente a 8,3 e 9,0 $\mathrm{t} \mathrm{ha}^{-1}$, respectivamente (Novo, 2004). Em estudos realizados por Azania et al., (2006), foi verificado que a viabilidade dos tubérculos de tiririca foi reduzida na ausência da cobertura com palha da cana-de-açúcar quando a profundidade do plantio era mais superficial. Isso se deveu a maior incidência de luz solar sobre os tubérculos e maior exposição destes ao herbicida testado.

Nas condições brasileiras não há muitos herbicidas registrados para a cana-de-açúcar 
que controlem com eficiência a tiririca (Rodrigues \& Almeida, 2005). O sulfentrazone é registrado no Brasil para o controle de mono e dicotiledôneas na cultura da cana-de-açúcar, soja, citros, café, eucalipto e em áreas não agrícolas. A absorção do produto ocorre pelo sistema radicular, sendo um produto sistêmico e de contato.

Flazasulfuron é registrado para o controle de mono e dicotiledôneas nas culturas de canade-açúcar e tomate, em pré ou pós-inicial, dependendo da cultura. Inibe a ação da enzima acetolactato síntese, precursora da formação de três aminoácidos essenciais ao desenvolvimento das plantas: valina, leucina e isoleucina, resultando na interrupção da divisão celular e no crescimento da planta. (Rodrigues \& Almeida, 2005). Embora a absorção do flazasulfuron possa ocorrer tanto via foliar quanto radicular, as aplicações em préemergência parecem depender de melhores condições de umidade do solo para surtirem o efeito desejado (Ferreira et al., 1999).

Azania et al. (2006), avaliando a viabilidade de tubérculos de tiririca tratados com diversos herbicidas, observaram que, sem cobertura de palha, quando foi aplicado trifloxysulfuron-sodium + ametryne nas doses de $1.312,5$ e $1.500 \mathrm{~g} \mathrm{ha}^{-1}$ da mistura dos herbicidas, as porcentagens de dissemínulos não viáveis foram de 52,8 e $55,2 \%$ respectivamente. Com a aplicação dos herbicidas halosulfuron, MSMA, 2,4-D e imazapic, os porcentuais de tubérculos não viáveis variaram entre $38,8,14,4,7,6$ e $29,2 \%$ respectivamente. Sulfentrazone proporcionou redução semelhante $(52,8 \%)$ às evidenciadas para a mistura de trifloxysulfuron-sodium + ametryne (Durigan et al., 2004).

Durigan et al. (2005) observou que quando sulfentrazone e imazapic foram aplicados exclusivamente no solo, havia menor número de tubérculos viáveis, diferindo significativamente dos herbicidas trifloxysulfuron-sodium + ametrine $\mathrm{e}$ halosulfuron. Para esses herbicidas, as aplicações restritas à parte aérea das plantas, proporcionaram maior perda da viabilidade de tubérculos. Todos os herbicidas apresentaram efeito deletério sobre o número de tubérculos (totais e viáveis), sendo observado que os melhores desempenhos estavam relacionados aos meios de absorção, translocação e ação, ou seja, houve relação direta entre as características dos produtos e os efeitos esperados.

Dessa forma, a perda da viabilidade dos tubérculos, soma das ações por ambos os meios, foram obtidos, com os herbicidas trifloxysulfuron-sodium + ametrine $(88,9 \%)$, sulfentrazone $(83,3 \%)$, imazapic $(80,6 \%)$ e halosulfuron (77,8\%) (Durigan et al., 2005a).

Segundo Durigan et al. (2005b), a capacidade de inviabilização de tubérculos de tiririca apresentada pelos herbicidas sulfentrazone (78\%), trifloxysulfuron-sodium + ametryne (70\%), imazapic (64\%) e halosulfuron $(50 \%)$ os credencia para a recomendação em aplicações isoladas ou de manejo integrado desta planta daninha.

O objetivo do trabalho foi verificar o efeito dos herbicidas sulfentrazone e flazasulfuron, aplicados isoladamente e em mistura, em pós-emergência inicial da tiririca sobre a viabilidade dos tubérculos.

\section{Material e métodos}

O experimento foi realizado nos anos agrícolas de 2003/2004 e 2004/2005, em canaplanta de doze meses e cana-soca, no campo, no município de Araras, SP, em área com Latossolo Vermelho, com $61 \%$ de argila, $24 \%$ de areia e $15 \%$ de silte, cuja análise de fertilidade encontra-se na Tabela 1 . O solo foi corrigido e adubado de acordo com as recomendações de Raij et al. (1996). 
Tabela 1 - Resultados das análises de fertilidade de amostras de terra coletadas na camada entre 0,0 a $0,2 \mathrm{~m}$ de profundidade, em Araras, SP

\begin{tabular}{|c|c|c|c|c|c|c|c|c|c|}
\hline \multicolumn{8}{|c|}{ Macronutrientes } \\
\hline $\mathrm{P}$ & M.O. & $\mathrm{pH} \mathrm{CaCl}_{2}$ & $\mathrm{~K}$ & $\mathrm{Ca}$ & $\mathrm{Mg}$ & $\mathrm{H}+\mathrm{Al}$ & $\mathrm{SB}$ & $\mathrm{CTC}$ & $\mathrm{V}$ \\
\hline$\left(\mathrm{mg} \mathrm{dm}^{-3}\right)$ & $\left(\mathrm{g} \mathrm{dm}^{3}\right)$ & & \multicolumn{7}{|c|}{$\left(\mathrm{mmol}_{\mathrm{c}} \mathrm{dm}^{3}\right)$} \\
\hline 12 & 31 & 4,8 & 0,2 & 28 & 9 & 52 & 89,2 & 37,2 & 42 \\
\hline
\end{tabular}

O experimento foi disposto no campo em blocos ao acaso, com seis repetições sendo cada parcela constituída de seis linhas de canade-açúcar espaçadas de $1,5 \mathrm{~m}$ e com seis metros de comprimentos, considerando-se como área útil as quatro linhas centrais. Os tratamentos estudados foram: uma testemunha sem capina e sem herbicida, sulfentrazone a $800 \mathrm{~g} \mathrm{ha}^{-1}$, sulfentrazone a $500 \mathrm{~g} \mathrm{ha}^{-1}+$ flazasulfuron a $37,5 \mathrm{~g} \mathrm{ha}^{-1}$, sulfentrazone a 400 $\mathrm{g} \mathrm{ha}+$ flazasulfuron a $37,5 \mathrm{~g} \mathrm{ha}^{-1}$, sulfentrazone a $300 \mathrm{~g} \mathrm{ha}^{-1}+$ flazasulfuron a $37,5 \mathrm{~g}$ ha-1, flazasulfuron a $50 \mathrm{~g} \mathrm{ha}^{-1} \mathrm{e}$ flazasulfuron $50 \mathrm{~g} \mathrm{ha}^{-1}, 30$ dias após mais $50 \mathrm{~g}$ $\mathrm{ha}^{-1}$ de flazasulfuron. Para a aplicação dos produtos utilizou-se equipamento costal pressurizado $\left(\mathrm{CO}_{2}\right)$, munido de barra com três bicos Teejet DG 110.02VS, espaçados de 50 $\mathrm{cm}$, mantido à altura de $50 \mathrm{~cm}$ do solo, a pressão $2,6 \mathrm{kgf} \mathrm{cm}^{-2}$ com volume de calda equivalente a $240 \mathrm{~L} \mathrm{ha}^{-1}$. Os produtos foram aplicados em pós-emergência inicial da tiririca (4 a 5 folhas emergidas) e da cultura de canade-açúcar SP801842 em cana-planta e reaplicado em cana-soca, nas mesmas condições.

Aos 90 e 300 dias após o tratamento (DAT) em 2004 e aos 90 e 270 DAT em 2005, em cada parcela, foram coletados tubérculos em área de 0,25 por $0,25 \mathrm{~m}$ e na profundidade de $0,25 \mathrm{~m}$. Em casa-de-vegetação, os tubérculos foram plantados em bandeja de poliestreno com 128 células preenchidas com substrato agrícola. Vinte dias após o plantio avaliou-se a emergência de brotações da tiririca, sendo determinado o seu porcentual.

Os dados foram submetidos à análise de variância pelo teste $\mathrm{F}$. As médias dos tratamentos, quando significativas, foram comparadas pelo teste $\boldsymbol{t}$, ao nível de $5 \%$ de probabilidade. Foram comparados os seguintes contrastes: testemunha vs sulfentrazone $800 \mathrm{~g}$ $\mathrm{ha}^{-1}$, testemunha vs flazasulfuron $50 \mathrm{~g} \mathrm{ha}^{-1}$, testemunha vs média das misturas, sulfentrazone $800 \mathrm{~g} \mathrm{ha}^{-1}$ vs flazasulfuron $50 \mathrm{~g}$ $\mathrm{ha}^{-1}$, sulfentrazone $800 \mathrm{~g} \mathrm{ha}^{-1}$ vs flazasulfuron $50+50 \mathrm{~g} \mathrm{ha}^{-1}$, sulfentrazone $800 \mathrm{~g} \mathrm{ha}^{-1}$ vs média das misturas, flazasulfuron $50 \mathrm{~g} \mathrm{ha}^{-1} \mathrm{vs}$ flazasulfuron $50+50 \mathrm{~g} \mathrm{ha}^{-1}$, flazasulfuron $50 \mathrm{~g}$ $\mathrm{ha}^{-1}$ vs média das misturas e flazasulfuron $50+$ $50 \mathrm{~g} \mathrm{ha}^{-1}$ vs média das misturas.

\section{Resultados e discussão}

Na Tabela 2 estão apresentadas as médias da viabilidade dos tubérculos e a porcentagem de controle destes em relação à testemunha nas avaliações realizadas em 2004 e 2005. Em 2004, aos 90 DAT, verificou-se redução na viabilidade dos tubérculos de $17,5 \%$ para o sulfentrazone isolado, de $43,9 \%$ para flazasulfuron isolado e de $53,8 \%$ para aplicações sequenciais de flazasulfuron $(50+$ $\left.50 \mathrm{~g} \mathrm{ha}^{-1}\right)$. As aplicações de flazasulfuron a $37,5 \mathrm{~g} \mathrm{ha}^{-1} \mathrm{com}$ as diferentes doses de sulfentrazone mostrou reduções na viabilidade inferiores a $30 \%$. Resultados superiores de controle foram obtidos por Costa et al. (1995) que demonstraram que com a aplicação de 60 
gha $^{-1}$ de flazasulfuron, aos 45 DAT, o controle foi de $85,5 \%$. Quanto ao número de tubérculos viáveis, esses autores observaram redução de (2006) obtiveram baixo nível na redução da viabilidade de dissemínulos de tiririca com a aplicação de $800 \mathrm{~g} \mathrm{ha}^{-1}$ de sulfentrazone sendo $43,2 \%$ para flazasulfuron. Durigan et al. observado decréscimo de apenas $18 \%$.

Tabela 2 - Efeito dos tratamentos na viabilidade de tubérculos de tiririca e na percentagem de redução da viabilidade de tubérculos tiririca aos 90 e 300 DAT em cana-planta em 2004. Dados médios de seis repetições.

\begin{tabular}{|c|c|c|c|c|}
\hline \multirow[b]{2}{*}{ Tratamentos } & \multicolumn{4}{|c|}{ Viabilidade de Tubérculos } \\
\hline & 90 DAT & Reduçã & 300 DAT & Redução \\
\hline Testemunha absoluta (sem capina) & 81,0 & 0,0 & 87,0 & 0,0 \\
\hline Sulfentrazone 800 g.ha $^{-1}$ & 66,8 & 17,5 & 85,9 & 1,3 \\
\hline Sulfentrazone $500 \mathrm{~g} \cdot \mathrm{ha}^{-1}+$ flazasulfuron $37,5 \mathrm{~g} \cdot \mathrm{ha}^{-1}$ & 62,5 & 22,8 & 79,5 & 8,6 \\
\hline Sulfentrazone 400 g.ha $^{-1}+$ flazasulfuron 37,5 g.ha $^{-1}$ & 61,2 & 24,4 & 76,5 & 12,1 \\
\hline Sulfentrazone $300 \mathrm{~g} \cdot \mathrm{ha}^{-1}+$ flazasulfuron $37,5 \mathrm{~g} \cdot \mathrm{ha}^{-1}$ & 65,4 & 19,3 & 73,6 & 15,4 \\
\hline Flazasulfuron $50{\mathrm{~g} . h \mathrm{~h}^{-1}}^{-1}$ & 45,4 & 43,9 & 60,7 & 30,2 \\
\hline Flazasulfuron 50 g.ha $^{-1}+$ flazasulfuron 50 g.ha $^{-1}$ & 37,4 & 53,8 & 54,9 & 36,9 \\
\hline
\end{tabular}

Aos 300 DAT, em 2004, em função da menor ação dos herbicidas devido à perda de sua atividade residual, não houve decréscimo na viabilidade dos tubérculos da tiririca com todos os produtos estudados (Tabela 2) sendo o melhor resultado obtido com a aplicação seqüencial de flazasulfuron mas, mesmo este produto apresentou redução de 36,9\% na viabilidade dos tubérculos de tiririca. Segundo Silva et al. (1995), com a aplicação seqüencial de flazasulfuron, realizada 30 dias após a primeira aplicação, a eficiência de controle de C. rotundus e C. esculentum foi significativamente aumentada atingindo $90 \%$ aos 28 dias após a segunda aplicação.

A viabilidade dos tubérculos em casa-devegetação, detectou-se reduções aos 90 DAT entre $17,5 \%$ para o sulfentrazone isolado e $53,8 \%$ para aplicações seqüenciais de flazasulfuron $\left(50+50 \mathrm{gha}^{-1}\right)$, aos 300 DAT em 2004, variaram respectivamente entre $1,3 \%$ a $36,9 \%$. Com a mistura de sulfentrazone + flazasulfuron, a redução na viabilidade dos tubérculos variou entre 19,3 a 24,4\%. (Tabela 2). Resultados semelhantes foram obtidos por Costa et al. (1995), nas doses de $60 \mathrm{gha}^{-1}$ de flazasulfuron e a dose de 540 gha $^{-1}$ de glifosate apresentaram aos 45 DAA controle de $85,5 \%$ e $68,9 \%$, respectivamente.

Quanto ao número de tubérculos viáveis verificou-se redução de $43,2 \%$ para flazasulfuron e apenas 2,2\% para o glifosate. Durigan et al. (2006), obtiveram reduções de viabilidade de dissemínulos com os tratamentos trifloxysulfuron-sodium + ametryne $\left(1,5 \mathrm{~kg} \mathrm{ha}^{-1}\right)$ de $22 \%$, sulfentrazone $\left(800 \mathrm{gha}^{-1}\right)$ de $18 \%$ e glifosate (duas aplicações de $1,44 \mathrm{~kg} \mathrm{ha}^{-1}$ ) de $7 \%$. Carvalho et al. (2005), observaram que o herbicida flazasulfuron foi eficiente no controle de C.rotundus até os 45 ou 90 DAPA, conforme o tratamento. Nas doses de 50 e $75 \mathrm{~g} \mathrm{ha}^{-1} \mathrm{o}$ herbicida foi eficiente até os 45 DAPA, com nível médio de controle acima de $88 \%$. Nas 
doses de $100 ; 125 ; 150 ; 37,5+37,5 ; 50+50$; $62,5+62,5$ e $75+75 \mathrm{~g} \mathrm{ha}^{-1}$, o herbicida foi eficiente no controle de $C$. rotundus até os 90 DAPA proporcionando níveis médios de controle de $85 \%, 91 \%, 91 \%, 94 \%, 94 \%, 96 \%$ e $99 \%$,respectivamente, esses tratamentos proporcionaram redução média do número de tubérculos de tiririca na ordem de $80 \%$.

Segundo Durigan (2005a), os herbicidas sulfentrazone e imazapic quando aplicado exclusivamente no solo, resultaram em menor número de tubérculos viáveis. Ao contrário, para as aplicações restritas à parte aérea das plantas, os herbicidas trifloxysulfuron-sodium + ametrine e halosulfuron proporcionaram maior perda da viabilidade de tubérculos.

Quanto às aplicações feitas na parte aérea e no solo, não houve diferença significativa entre os herbicidas estudados, porém todos diferiram da testemunha. Os herbicidas apresentaram efeito deletério sobre o número de tubérculos (totais e viáveis), com melhores performances relacionadas às suas principais formas de absorção, translocação e ação, ou seja, houve relação direta entre as características dos produtos e os efeitos esperados. Dessa forma, o sulfentrazone e o imazapic foram mais eficazes pelo solo, enquanto o trifloxysulfuron-sodium + ametrine e o halosulfuron o foram quando aplicados na parte aérea. Os melhores resultados finais, ou seja, a perda da viabilidade dos tubérculos, soma das ações por ambos os meios, foram obtidos, em ordem decrescente, com os herbicidas trifloxysulfuron-sodium + ametrine $(88,9 \%)$, sulfentrazone $(83,3 \%)$, imazapic $(80,6 \%)$ e halosulfuron $(77,8 \%)$.

Durigan et al. (2006), concluíram que a utilização de implementos mecânicos (arado + grade) na época "seca" potencializou a ação dos herbicidas trifloxysulfuron-sodium + ametryne e sulfentrazone nas "águas", porém esses herbicidas já resolvem o problema do controle, evitando reduções de produção e diminuindo gradativamente o potencial de infestação, com aplicações individualizadas por época do plantio da cultura.

Esses resultados comprovam a maior eficiência dos herbicidas nas plantas de tiririca, que sofreram quebra da dominância apical devido o preparo do solo em canaplanta e consequentemente estavam mais susceptíveis a ação dos herbicidas.

Em 2005 em cana-soca, tanto aos 90 como aos 270 DAT, as redução na viabilidade de tubérculos na maioria dos tratamentos herbicidas foram menores em relação a canaplanta, esse resultados foram influenciados pela condições de aplicação, que normalmente são utilizados na condução da cultura da canade-açúcar, o qual não se utiliza do revolvimento do solo, diferentemente das condições em cana-planta.

Cordeiro et al. (2006) constataram que o número de $C$. rotundus nos tratamentos sob plantio direto foram inferiores aos observados na área com preparo convencional, provavelmente, devido à partição dos tubérculos e rizomas e ausência de cobertura vegetal na superfície do solo, além de grande variação térmica do solo que favorece a brotação de $C$. rotundus. Destaca-se também que no sistema plantio direto houve efeito físico da cobertura morta e da não partição de tubérculos de $C$. rotundus, uma vez que não ocorreu preparo mecânico do solo. A mesma situação ocorre em cana-soca, uma vez que não é realizado o revolvimento do solo, como acontece na cana-planta.

$\mathrm{Na}$ reaplicação dos tratamentos em 2005 foram observadas reduções de viabilidade de tubérculos aos 90 DAT entre $1,6 \%$ a $31,5 \%$ e aos 270 DAT entre $2,3 \%$ e $36,1 \%$ (Tabela 3 ).

$\mathrm{O}$ efeito da aplicação de herbicidas em cana-soca para o controle específico da tiririca, pode ser prejudicado pelo maior número de ramificações das "cadeias" de tubérculos, 
devido ao não revolvimento do solo e também pela dificuldade de translocação do herbicidas através dos tubérculos que estão em dormência. Como demonstram os resultados obtidos por Durigan et al. (2005a), avaliando o terceiro tubérculo da "cadeia" presa à manifestação epígea original, foi afetado em 92,95 e $65 \%$, pelo trifloxysulfuron-sodium + ametrine, nos estádios de aplicação "jovem", em pré-florescimento e florescimento pleno, respectivamente. Esses resultados foram de 70, 82 e $68 \%$ para o glifosate e de 62,54 e $46 \%$ para o halosulfuron. No terceiro tubérculo da "cadeia" presa à manifestação epígea derivada, os percentuais foram de 79,74 e $70 \%$ para o trifloxysulfuron-sodium + ametrine; $68,71 \mathrm{e}$ $57 \%$ para o glifosate; e 60,51 e $41 \%$ para o halosulfuron, quando aplicados nos estádios "jovem", de pré-florescimento e de florescimento pleno, respectivamente.

Tabela 3 - Efeito dos tratamentos na viabilidade de tubérculos de tiririca e na percentagem de redução da viabilidade de tubérculos tiririca aos 90 e 270 DAT em cana-soca em 2005. Dados médios de seis repetições.

\begin{tabular}{|c|c|c|c|c|}
\hline \multirow{2}{*}{ Tratamentos } & \multicolumn{4}{|c|}{ Viabilidade de Tubérculos } \\
\hline & 90 DAT & Redução & $270 \mathrm{DAT}$ & Redução \\
\hline Testemunha absoluta (sem capina) & 79,9 & 0,0 & 83,9 & 0,0 \\
\hline Sulfentrazone 800 g.ha $^{-1}$ & 78,6 & 1,6 & 73,9 & 11,9 \\
\hline Sulfentrazone $500 \mathrm{~g} \cdot \mathrm{ha}^{-1}+$ flazasulfuron $37,5 \mathrm{~g} \cdot \mathrm{ha}^{-1}$ & 69,8 & 12,7 & 82,0 & 2,3 \\
\hline 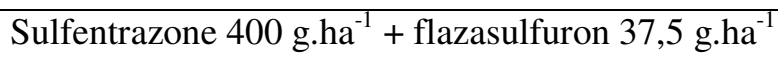 & 74,2 & 7,2 & 76,0 & 9,4 \\
\hline Sulfentrazone $300 \mathrm{~g} \cdot \mathrm{ha}^{-1}+$ flazasulfuron $37,5 \mathrm{~g} \cdot \mathrm{ha}^{-1}$ & 71,3 & 10,8 & 71,9 & 14,3 \\
\hline Flazasulfuron $50 \mathrm{~g}$.ha ${ }^{-1}$ & 69,9 & 12,5 & 68,6 & 18,2 \\
\hline${\text { Flazasulfuron } 50 \text { g.ha }^{-1}+\text { flazasulfuron } 50 \text { g.ha }}^{-1}$ & 54,7 & 31,5 & 53,6 & 36,1 \\
\hline
\end{tabular}

Os resultados de redução da viabilidade proporcionada pelo sulfentrazone $800 \mathrm{gha}^{-1}$, apresentou diferença significativas até 90 DAT em cana-planta, não ocorrendo nas demais avaliações em cana-planta aos 300 DAT, em 2004 e, reaplicação cana-soca aos 90 e 270 DAT, reaplicados em 2005, foi observada baixa redução na viabilidade de tubérculos de C. rotundus, não ocorrendo diferenças estatísticas em relação à testemunha nas condições em que se realizaram os experimentos.

Os tratamentos com mistura de sulfentrazone + flazasulfuron apresentaram diferenças significativas em relação a testemunha até aos 300 DAT em cana-planta, mas não houve diferença estatística em relação a testemunha em cana-soca.

O tratamento flazasulfuron $50 \mathrm{~g} \mathrm{ha}^{-1}$, apresentou diferença significativas em relação a testemunha em cana-planta até 300 DAT, mas não diferenciou-se da testemunha em cana-soca. No caso das aplicações seqüenciais de flazasulfuron $50 \mathrm{~g} \mathrm{ha}^{-1}+$ flazasulfuron $50 \mathrm{~g}$ $\mathrm{ha}^{-1}$, foi $\mathrm{o}$ tratamento que apresentou diferenças significativas em todas as avaliações em relação a testemunha e ao tratamento sulfentrazone, nas condições em que se realizaram os experimentos (Tabela 4).

$\mathrm{Na}$ Tabela 4 está apresentada a comparação dos diferentes contrastes analisados e a significância destes. 
Os resultados apresentados pelo herbicida sulfentrazone $800 \mathrm{~g}$ ha $^{-1}$, sulfentrazone $500 \mathrm{~g} \mathrm{ha}^{-1}+$ flazasulfuron $37,5 \mathrm{~g}$ $\mathrm{ha}^{-1}$, sulfentrazone $400 \mathrm{~g} \mathrm{ha}^{-1}+$ flazasulfuron $37,5 \mathrm{~g} \mathrm{ha}^{-1}$, sulfentrazone $300 \mathrm{~g} \mathrm{ha}^{-1}+$ flazasulfuron $37,5 \mathrm{~g} \mathrm{ha}^{-1}$, flazasulfuron $50 \mathrm{~g}$ $\mathrm{ha}^{-1}$ e flazasulfuron $50 \mathrm{~g} \mathrm{ha}^{-1}+$ flazasulfuron $50 \mathrm{~g} \mathrm{ha}^{-1}$ demonstraram redução na viabilidade de tubérculos até aos 90 DAT em 2004, diferenciaram estatisticamente da testemunha. Nas avaliações de 300 DAT, em 2004 e, aos 90 e 270 DAT, reaplicados em 2005, apresentaram baixa redução na viabilidade de tubérculos de $C$. rotundus, não havendo diferenças estatísticas em relação à testemunha nas condições em que se realizaram os experimentos, com exceção das aplicações seqüenciais de flazasulfuron $50 \mathrm{~g}$ $\mathrm{ha}^{-1}+$ flazasulfuron $50 \mathrm{~g} \mathrm{ha}^{-1}$, que apresentaram diferenças significativas (Tabela 4). Os tratamentos com flazasulfuron aplicado em uma única dose de $50 \mathrm{~g} \mathrm{ha}^{-1}$ ou sequencialmente, ocasionaram reduções significativas na viabilidade dos tubérculos aos 90 e 300 DAT em 2004. Os melhores resultados em cana-soca, para a redução da viabilidade de tubérculos foram obtidos pelas aplicações seqüenciais de flazasulfuron $50 \mathrm{~g}$ $\mathrm{ha}^{-1}+$ flazasulfuron $50 \mathrm{~g} \mathrm{ha}^{-1}$.

Tabela 4 - Comparação das médias empregando-se o teste $t$ para efeito de sulfentrazone e flazasulfuron, quando à percentagem de tubérculos viáveis aos 90 e 300 DAT em canaplanta e aos 90 e 270 DAT em cana-soca. Dados médios de seis repetições. 2004 e 2005.

\begin{tabular}{|c|c|c|c|c|}
\hline \multirow[b]{2}{*}{ Contraste } & \multicolumn{4}{|c|}{ Viabilidade de Tubérculos (\%) } \\
\hline & $\begin{array}{c}\text { 90 DAT } \\
2004\end{array}$ & $\begin{array}{c}\text { 300 DAT } \\
2004\end{array}$ & $\begin{array}{c}\text { 90 DAT } \\
2005\end{array}$ & $\begin{array}{c}270 \text { DAT } \\
2005\end{array}$ \\
\hline Testemunha vs sulfentrazone 800 g.ha ${ }^{-1}$ & 81,0 vs $66,8^{* *}$ & 87,0 vs 85,9 & 79,9 vs 78,6 & 83,9 vs 73,9 \\
\hline Testemunha vs flazasulfuron 50 g.ha ${ }^{-1}$ & 81,0 vs $45,4 * *$ & 87,0 vs $60,7 * *$ & 79,9 vs 69,9 & 83,9 vs 68,6 \\
\hline Testemunha vs média das misturas & 81,0 vs $63,0^{* *}$ & 87,0 vs $76,5^{* *}$ & 79,9 vs 71,9 & 83,9 vs 76,6 \\
\hline Sulfentrazone 800 g.ha $^{-1}$ vs flazasulfuron 50 g.ha $^{-1}$ & 66,8 vs $45,4 * *$ & 85,9 vs $60,7 * *$ & 78,6 vs 69,9 & 73,9 vs 68,6 \\
\hline Sulfentrazone 800 g.ha ${ }^{-1}$ vs flazasulfuron $50+50$ g.ha ${ }^{-1}$ & 66,8 vs $37,4^{* * *}$ & 85,9 vs $54,9 * *$ & 78,6 vs $54,7 * *$ & 73,9 vs $53,6^{*}$ \\
\hline Sulfentrazone 800 g.ha $^{-1}$ vs média das misturas & 66,8 vs 63,0 & 85,9 vs $76,5^{*}$ & 78,6 vs 71,9 & 73,9 vs 76,6 \\
\hline Flazasulfuron $50 \mathrm{~g} \cdot \mathrm{ha}^{-1}$ vs flazasulfuron $50+50 \mathrm{~g} \cdot \mathrm{ha}^{-1}$ & 45,4 vs 37,4 & 60,7 vs 54,9 & 69,9 vs 54,7 & 68,6 vs 53,6 \\
\hline 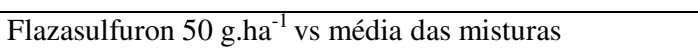 & 45,4 vs $63,0^{* *}$ & 60,7 vs $76,5^{* * *}$ & 69,9 vs 71,9 & 68,6 vs 76,6 \\
\hline Flazasulfuron $50+50$ g.ha $^{-1}$ vs média das misturas & 37,4 vs $63,0^{* *}$ & 54,9 vs $76,5^{* * *}$ & 54,7 vs $71,9 * *$ & 53,6 vs $76,6^{* *}$ \\
\hline
\end{tabular}

* (significativo a $5 \%$ de probabilidade) $\quad * *$ (significativo a $1 \%$ de probabilidade) 90 DAT $2004 \mathrm{CV}=12,42 ; 300$ DAT CV $=$ 10,$40 ; 90$ DAT $2005 \mathrm{CV}=18,45 ; 270 \mathrm{DAT} \mathrm{CV}=22,41$. 


\section{Conclusões}

Concluiu-se que o herbicida flazasulfuron, em aplicações isoladas ou seqüenciais, foi o tratamento mais eficaz em reduzir a viabilidade dos tubérculos de tiririca.

\section{Referências}

ARÉVALO, R.A. Recentes avanços em controle químico em controle químico de Cyperus rotundus (tiririca) em Saccharum spp (cana-de-açúcar). In: Congresso Nacional da Sociedade dos Técnicos Açucareiros e Alcooleiros do Brasil - STAB, 6, Maceió. Resumos... p.356 - 360, 1996.

AZANIA, C. A. M. et al. Desenvolvimento da tiririca (Cyperus rotundus) influenciado pela presença e ausência de palha de cana-deaçúcar e herbicida. Planta Daninha, v.24, n.1, p.29-35, 2006.

BARUIAN, J. V. et al. Glyphosate injury, rainfastness, absorption, and translocation in purple nutsedge (Cyperus rotundus). Weed Technology, v.13, n.3, p.112-119, 1999.

BENDIXEN, L. E.; NANDIHALLI, U. B. Worldwide distribution of purple and yellow nutsedge (Cyperus rotundus and $C$. esculentus). Weed Technology, v.1, n.1, p.6165, 1987.

CARVALHO, F.T. et al. Eficácia do herbicida flazasulfuron no controle de plantas daninhas em cana-de-açúcar e seus efeitos no crescimento e produtividade da cultura. Revista Brasileira de Herbicidas, v.4, n.1, p.78-88, 2005.

CATUNDA, M.G. et al. Influência do extrato aquoso de Cyperus rotundus na germinação de sementes e na divisão celular do meristema radicular de alface. In: Congresso Brasileiro da Ciência das Plantas Daninhas, 22., Foz do Iguaçu. Resumos... p.78, 2000.
CORDEIRO, L.A.M. et al. Efeito do plantio direto no controle de tiririca (Cyperus rotundus L.) e outras plantas daninhas na cultura do milho. Revista Brasileira de Herbicidas, n.1, p.1-9, 2006.

COSTA, E.R. et al. Efeitos do flazasulfuron e do glifosate em aplicações únicas e seqüenciais sobre o controle da tiririca (Cyperus rotundus L.). In: Congresso Brasileiro da Ciência das Plantas Daninhas, 20., Florianópolis. Resumos... p. 395, 1995.

DARIO, G. J. A. et al. Controle da tiririca (Cyperus rotundus) na cultura da cana-deaçúcar (Saccharum officinarum). In: Congresso Brasileiro da Ciência das Plantas Daninhas, 20., 1995, Florianópolis. Resumos... p. 198, 1995.

DEUBER, R. Ciência das plantas infestantes: fundamentos $2^{\mathrm{a}}$ ed. Funep, Jaboticabal, p107, 2003.

DURIGAN, J. C. Manejo da tiririca (Cyperus rotundus L.) antes e durante a implantação da cultura de cana-de-açúcar (Saccharum spp.). Tese (livre-docência) UNESP, Jaboticabal, 1991.

DURIGAN, J. C.; CORREIA, N. M.; TIMOSSI, P. C. Estádios de desenvolvimento e vias de contato e absorção dos herbicidas na inviabilização de tubérculos de Cyperus rotundus. Planta Daninha, v.23, n.4, p.621626. $2005 \mathrm{a}$.

DURIGAN, J.C.; TIMOSSI, P.C.; CORREIA, N.M. Densidades e manejo químico da tiririca na produtividade de cana-de-açúcar. Planta Daninha, v.23, n.3, p.463-469. 2005b

DURIGAN, J.C.; TIMOSSI, P.C.; CORREIA, N.M. Manejo integrado da tiririca na produtividade de cana-de-açúcar. Planta Daninha, v.24, n.1, p.77-81, 2006.

DURIGAN, J. C.; TIMOSSI, P. C.; LEITE, G. J. Controle químico da tiririca (Cyperus rotundus), com e sem cobertura do solo pela 
palha de cana-de-açúcar. Planta Daninha, v.22, n.1, p.127-135. 2004.

FERREIRA, F. A. et al. Flazasulfuron: época e doses de aplicação em relação ao controle de plantas daninhas e seletividade para cana-deaçúcar (Saccharum spp.). STAB -Açúcar álcool e Subprodutos, v.17, n.5, p.44-47, 1999.

HOLM, L. G. et al. The world's worst weeds: distribution and biology. Honolulu: University Press Hawaii, 1977. 609 p.

KISSMANN, K. G. Plantas infestantes e nocivas. tomo I 2. ed. São Paulo. Basf p.222229, 1997.

LORENZI, H. Plantas daninhas do Brasil: terrestres, aquáticas, parasíticas e tóxicas. 3 ed. Nova Odessa: Instituto Plantarum, 2000. p.251.

MACHADO, A.F.L. et al. Misturas de herbicidas no manejo de plantas daninhas na cultura do feijão. Planta Daninha, v.24, n.1, p.107-114. 2006.

NOVO, M. C. S. S. Efeito da palha de canade-açúcar e do tamanho de tubérculos no desenvolvimento da tiririca (Cyperus rotundus L.). Tese (Doutorado) - Escola Superior de Agricultura "Luiz de Queiroz" Universidade de São Paulo, Piracicaba, 2004.

RODRIGUES, B. N.; ALMEIDA, F. S. Guia de herbicidas, Londrina-PR, $4^{\text {a }}$ ed., 1998. 591 p.

ROLIM, J.C.; GONÇALVES, C.P.; CORBO, E. Interferência da tiririca (Cyperus rotundus L.) na cultura da cana-de-açúcar (Saccharum spp). In: Congresso Brasileiro da Ciência das Plantas Daninhas, 23, Gramado. Resumos... p. 60, 2002.

SILVA, A. A. et al. Tolerância da cana-deaçúcar (Saccharum spp.) ao flazasulfuron em aplicações isoladas, seqüenciais e em misturas com outros herbicidas e seus efeitos sobre a tiririca (Cyperus rotundus L.) e outras espécies de plantas daninhas. In: Congresso Brasileiro da Ciência das Plantas Daninhas, 20., Florianópolis. Resumos... p. 243, 1995.

SILVA, C. A. R. et al. Competição entre biótipos de tiririca (Cyperus rotundus). In: Congresso Brasileiro da Ciência das Plantas Daninhas, 22., Foz do Iguaçu. Resumos... p.51, 2000.

STOLLER, E. W.; SWEET, R. D. Biology and life cycle of purple and yellow nutsedge (Cyperus rotundus and C. esculentus). Weed Technology, v.1, n.3, p.66-73, 1987.

STOLLER, E. W.; WAX, L. M. Periodicity of germination and emergence of some annual weeds. Weed Science, v.21, n.4, p.574-580, 1973.

WILLS, G. D. Effect of light and temperature on growth of purple nutsedge. Weed Science, v. 23, n.1, p.93-96, 1975. 